\title{
Editorial: Collaborative Research to Address Changes in the Climate, Hydrology and Cryosphere of High Mountain Asia
}

\author{
Anthony Arendt ${ }^{1 *}$, Nir Krakauer ${ }^{2}$, Sujay V. Kumar ${ }^{3}$, David R. Rounce ${ }^{4}$ and Summer Rupper ${ }^{5}$ \\ ${ }^{1}$ University of Washington, Seattle, WA, United States, ${ }^{2}$ City College of New York (CUNY), New York, NY, United States, \\ ${ }^{3}$ Hydrological Sciences Laboratory, NASA Goddard Space Flight Center, Greenbelt, MD, United States, ${ }^{4}$ Carnegie Mellon \\ University, Pittsburgh, PA, United States, ${ }^{5}$ The University of Utah, Salt Lake, UT, United States
}

Keywords: cryosphere, high mountain Asia, snow, hydrology, hazards, climate

Editorial on the Research Topic

Collaborative Research to Address Changes in the Climate, Hydrology and Cryosphere of High Mountain Asia

High Mountain Asia (HMA) holds large reservoirs of glaciers and snow that provide water to over a billion people in the region. Local resource managers rely on accurate assessments of present and projected runoff to inform decisions, but observations needed to build these assessments are sparse. In recent years, increasingly high resolution remote sensing observations and land surface models have provided new approaches for assessing HMA's climate, hydrology and cryosphere. A central challenge of ongoing research is to develop innovative approaches to calibrate and validate remote sensing and model simulations.

Precipitation data are central to nearly every HMA hydrological assessment, but we lack information on the accuracy of existing products derived from models, satellites and ground stations. Christensen et al. use a Bayesian statistical model to quantify the shared spatial and temporal variability and uncertainty of these existing datasets, and they generate a combined product that assimilates the spatial and temporal structure of all models. Yoon et al. also intercompare existing precipitation products, showing that although they capture broad spatial patterns of precipitation, they exhibit large differences in their means and trends that need to be addressed in future reanalysis work.

Quantifying snow water equivalent (SWE) is necessary for irrigation and flood forecasting, and several papers explore ways to combine remote sensing data with snowpack simulation models. Margulis et al. present a new snow reanalysis approach that applies a scaling factor, derived from a model constrained by satellite-derived (from MODIS and Landsat) fractional snow covered area, to an existing snowfall product to estimate SWE. Using this approach, Liu and Margulis show that several existing snowfall datasets underestimate high elevation snowpacks, and they provide a roadmap for building a full HMA-wide snow reanalysis product. Remote sensing of microwave brightness temperatures provides another way to measure SWE. Rather than using a radiative transfer model to relate geophysical variables to brightness temperature measurements, Ahmad et al. use support vector machines to improve SWE estimates within an existing land surface model. Lund et al. explore the use of Synthetic Aperture Radar to measure HMA snow properties. The radar's ability to see through clouds is well-suited for monsoon regions and enables observations of transient snow line altitudes that offer additional constraints on snow and glacier evolution models. One way to improve these remote sensing and model assimilation studies is to directly observe snow depth at 
high elevations. Kirkham et al. deploy a gamma ray sensor to measure SWE directly at nearly 5,000 $\mathrm{m}$ a.s.l., and Saloranta et al. show how these observations can be used to directly parameterize a regional snow model. Khan et al. directly measure high elevation snowpack chemistry in an effort to assess the impacts of biofuel burning and subsequent deposition of black carbon on snow surface albedo.

Until recently the contribution of HMA glaciers to the total water budget has been poorly constrained. A comparison of digital elevation models derived from stereo satellite imagery shows that HMA glaciers lost $19.0 \pm 2.5 \mathrm{Gt} \mathrm{yr}^{-1}$ of mass between 2000-2018 (Shean et al.). Rounce et al. use these data to calibrate a glacier evolution model, providing projections of glacier mass change and runoff for four Representative Concentration Pathways (RCPs). They predict HMA glaciers will lose between $29 \pm 12 \%$ (RCP 2.6) to $67 \pm 10 \%$ (RCP 8.5) of their mass by 2,100 , relative to 2015 . Racoviteanu et al. assess HMA glacier health using semi-automatic methods to identify seasonal snow line altitudes on glaciers from optical satellite imagery. In addition to these regional assessments, several studies focus on a detailed analysis of specific glaciers to explore factors driving glacier changes. Wijngaard et al. model two HMA glaciers to show that glacier change during 1850-2016 was largely due to anthropogenic forcing, with greater impacts on the clean-ice glacier than the debris-covered glacier. Bonekamp et al. simulate glacier conditions in two contrasting catchments and find large regional mass balance variability that depends on complex variations in the surface energy balance. Calculating this energy budget for any given glacier depends strongly on the resolution of the digital elevation model (Olson et al.) and on accurate calculation of the surface albedo, especially for summeraccumulation type glaciers where the frequency of summer snowfall events can significantly alter the amount of shortwave radiation received at the surface (Johnson and Rupper). Many glaciers in HMA terminate in lakes that are now being monitored using uncrewed aerial vehicle surveys, providing data to quantify glacier calving losses into proglacial lakes and advance our understanding of the thermal and dynamic factors that control calving frequency (Watson et al.). These glacial lakes have varying reflectance spectra depending on factors such as lithic particles and phytoplankton, which Schiassi et al. forward model using remote sensing reflectance data, and inverse model using in situ observations.

Numerous manuscripts generate integrated assessments of the hydrology of the HMA region. Xue et al. assimilate snow cover and freeze/thaw remote sensing products into a hyper-resolution $(1 \mathrm{~km})$ land surface model. They find the assimilation improves model estimates relative to ground validation observations, but that more high elevation ground observations are needed to significantly improve the model. Yoon et al. explore uncertainties in a suite of land surface models and find that hydrological estimates are highly sensitive to the quality of the meteorological forcing data. Loomis et al. use output from one model analyzed by Yoon et al. and combine it with independent observations of glaciers (Shean et al.) and groundwater variability. They develop a novel regression approach that uses satellite gravimetry data to assess the degree of closure of the modeled and observed water budget. A key outcome from this set of studies is that improved understanding of subsurface conditions such as permafrost degradation and groundwater depletion due to irrigation will improve our ability to partition the complex array of hydrological signals in HMA.

Narrowing in on specific watersheds, Kayastha et al. combine satellite scatterometry data with a glacier mass balance model to simulate runoff from snow and ice and assess model performance relative to local streamflow observations. Mishra et al. use a coupled biophysical and economic valuation model to assess the impacts of climate change on two different HMA river basins, and conclude that economic impacts depend strongly on the partitioning of meltwater between sources of rain, snow and ice melt. Stream isotope and chemistry data provide direct methods for measuring this meltwater partitioning, which Hill et al. demonstrate for portions of the Brahmaputra River Basin.

HMA's unique climatic, geomorphic and tectonic factors combine to create an interlinked array of potential hazards. Kirschbaum et al. provide a comprehensive survey of connections among hydrologic and geologic hazards in HMA, explain how they can be assessed using remote sensing data, and provide a roadmap of how to address current gaps in understanding. Future work calls for similar cross-disciplinary assessments that link together models and observations of HMA climate, hydrology and cryospheric processes to inform regional decision makers.

\section{AUTHOR CONTRIBUTIONS}

AA, NK, SK, DR, and SR collaborated to write the editorial.

\section{ACKNOWLEDGMENTS}

We acknowledge funding from NASA HMA NNX16AQ61G.

Conflict of Interest: The authors declare that the research was conducted in the absence of any commercial or financial relationships that could be construed as a potential conflict of interest.

Copyright (C) 2020 Arendt, Krakauer, Kumar, Rounce and Rupper. This is an openaccess article distributed under the terms of the Creative Commons Attribution License (CC BY). The use, distribution or reproduction in other forums is permitted, provided the original author(s) and the copyright owner(s) are credited and that the original publication in this journal is cited, in accordance with accepted academic practice. No use, distribution or reproduction is permitted which does not comply with these terms. 